\title{
Extinction in a passive avoidance task and its interaction with electroconvulsive shock'
}

\author{
F. ROBUSTELLI, ANNE GELLER, and M. \\ E. JARVIK, Albert Einstein College of \\ Medicine, Bronx, N.Y. 10461
}

A passive avoidance conditioned response was partially extinguished by giving mice a socially facilitated exploratory session for 10 min immediately after the training trial. Electroconvulsive shock (ECS) administered 10 min after the training trial also resulted in a decrease of the step-through latencies in the retest trial given $24 \mathrm{~h}$ later. When $E C S$ was administered at the end of the exploratory session, its amnesic effect on the conditioned response was greatly increased.

It has been shown that ECS administered after extinction or reversal results in an improvement of the original learning performance compared with the performance of animals given extinction or reversal only (Duncan, 1948; Bures, 1963 Gerbrandt \& Thomson, 1964; Greenough \& Schwitzgebel, 1966). This finding has been explained on the basis of a selective amnesic effect of ECS on the more recent experience, when two successive conflicting experiences are involved in the experimental procedure. Recent studies (Robustelli \& Jarvik, 1968), however, have led to opposite conclusions. In these studies, mice detained in the safe compartment of the conditioning apparatus immediately after a passive avoidance trial showed a decrease of step-through latencies in retest trials given $24 \mathrm{~h}$ later. A single ECS, administered immediately after the end of the detention period, did not decrease the amnesic effect of detention. On the contrary, amnesia produced by administering ECS after detention was found remarkably stronger than amnesia produced by either detention alone or ECS alone. Results suggested that the negative retroactive interference of detention with the passive avoidance training could be explained by hypothesizing that detention acted as a kind of generalized extinction.

The present study was designed to extend this line of research using a different interfering experience prior to ECS administration. A normal extinction trial would be preferred, but is not possible in our task, since most $\mathrm{Ss}$ do not make the step-through response the second time they are placed in the conditioning apparatus. In a preliminary experiment it was found that most animals did not show any exploratory behavior at all immediately after the passive avoidance trial, exhibiting an intense freezing reaction when put in a new environment. This is in agreement with what we know about the interaction between fear and exploratory activity (Baron, 1964). However, previous studies on the socially facilitated reduction of a fear response (Davitz \& Mason, 1955) suggested that the presence of other animals could inhibit the freezing reaction of the conditioned $S$ when put in a new environment, thus permitting it to explore. Furthermore, the assumption that one-trial learning procedures favor generalization processes makes it reasonable to predict that positive reinforcement of the exploratory behavior of the animal in whatever situation it can be elicited could have extinguishing properties for the passive avoidance conditioned response, previously acquired by negatively reinforcing the exploratory behavior. If this is true, we can test the effect of a single ECS given immediately after this extinction experience to check whether the performance of the original task is improved or impaired compared with the performance of the Ss given the extinction experience alone.

\section{SUBJECTS}

The Ss were 160 female CF 1 albino mice approximately 6 weeks old, housed 8 to a cage, with ad lib access to food and water.

\section{APPARATUS AND PROCEDURE}

The step-through apparatus consisting of a trough-shaped two-compartment box as described by Jarvik \& Kopp (1967) was used. In the smaller transparent compartment Ss were exposed to a bright Tensor lamp approximately $2 \mathrm{~cm}$ away. The smaller compartment was connected with the larger darkened compartment by an opening that could be closed by a guillotine door. The Ss were placed into the smaller lit compart ment facing away from the door and received a punishing shock $(350 \mu \mathrm{A})$ for stepping spontaneously into the larger darkened compartment. The step-through latencies were redetermined $24 \mathrm{~h}$ after the learning trial. Animals tarrying longer than $600 \mathrm{sec}$ were removed.

The exploration apparatus was a 9-in. square cardboard box, 5 in. high. In the center of the floor was a $2 \frac{1}{2}-\mathrm{in}$. cardboard cube. Holes $5 / 8$ in. in diam were drilled 1 in. off the floor, three to each wall and one to each exposed side of the central cube. The box was covered by a transparent Plexiglas top to permit observation of the Ss. Two naive animals were put in the exploration apparatus $2 \mathrm{~min}$ before the arrival of the $S$ which had been given the passive avoidance training trial so that, when the conditioned $S$ arrived, they were engaged in an active exploration. In this way, freezing behavior was completely neutralized in all passiveavoidance trained $S s$ and they started exploring as soon as they were put in the exploration apparatus. No quantitative measure of the exploratory activity of the Ss was taken, since this was not the concern of the present experiment. The behavior of the animals was, however, carefully observed in order to be sure that exploration was intense for the entire 10-min period.

Using a Hans electroshock apparatus $(2-\mathrm{C})$, ECS ( $15 \mathrm{~mA}$ for $0.2 \mathrm{sec})$, producing full tonic seizures, was administered transcorneally.

Four groups of animals were used with 20 animals in each group. The Ss of Group 1 were returned to their home cages immediately after the passive avoidance training trial and given a sham ECS $10 \mathrm{~min}$ later. The Ss of Group 2 were returned to their home cages immediately after the training trial and given ECS $10 \mathrm{~min}$ later. The Ss of Group 3 were placed in the exploration apparatus immediately after the training trial and were allowed to explore for $10 \mathrm{~min}$. They were then given sham ECS before being returned to their home cages. The Ss of Group 4 were treated as Group 3 except that they received ECS before being returned to their home cages.

\section{RESULTS}

The results of the retest trials are represented in Fig. 1. In Groups 2 and 3, in which ECS only or exploratory session only were given after the training trial, latencies are very similar and both are significantly lower (Wilcoxon \& Wilcox, 1964) than in Group 1, the control group (Group 2 vs Group 1, $p<0.01$; Group 3 vs Group 1 $\mathrm{p}<0.05)$. The latencies of Group 4, in which ECS was administered at the end of the exploratory session, are significantly lower than the latencies of all the other groups (vs Group 1, p $<0.01$; vs Group 2. $\mathrm{p}<0.05$; vs Group 3, p $<0.01$ ).

\section{DISCUSSION}

As predicted, the exploratory session, by giving a positive reinforcement to the exploratory behavior of the Ss, resulted in a reduction of the passive-avoidance conditioned response acquired by a negative reinforcement of exploratory behavior.

The occurrence of stimulus generalization processes in exploratory behavior has already been postulated by Montgomery (1953), and the finding that the effect of reinforcement given to a certain type of 


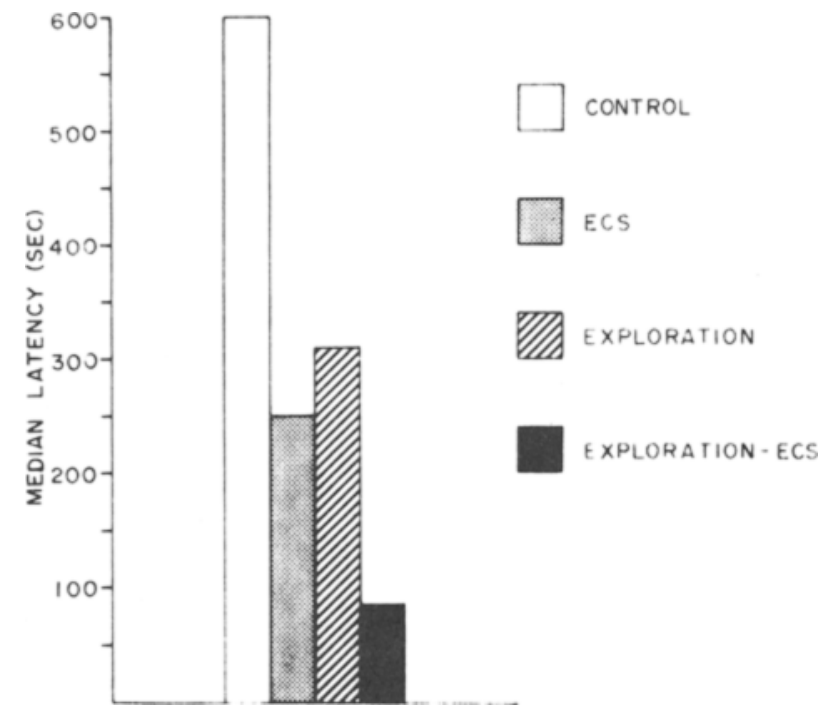

Fig. 1. Median retest latencies of mice $24 \mathrm{~h}$ after training.

behavior in one situation can be transferred to the same type of behavior in another situation is not surprising. In particular, in a single-trial learning situation, the $S$ is unlikely to be able to associate the reinforcement with the specific experimental situation in which learning has occurred. Thus, we assume that in our task being placed in a novel environment is a basic aspect of the learning experience and the animal's response to this would be associated with the subsequent punishment. The passive-avoidance training trial and the exploratory session can be thought to produce two conflicting types of associations, since an exploratory response to a new environment is negatively reinforced the first time and positively reinforced the second time. Obviously, the second association has a negative retroactive effect on the first one, which is therefore weakened.

The results of Group 2 show that the first association is also weakened by the following ECS administration. On the other hand, the results of Group 4 show that the first association is more weakened when ECS is administered immediately after the second association than when the second association alone or ECS alone is given. It could be concluded that, under our experimental conditions, a selective amnesic effect of ECS on the retention of the more recent experience does not occur. However, the particular procedure we have used has to be carefully considered. Most experiments which have shown a selective amnesic effect of ECS on the more recent learning experience either had a long interval between the first and the second experience and/or were lacking appropriate control groups which had been given ECS alone, without the second experience, at the same time interval after the original learning as in the group which had been given ECS after the second experience. Under the se circumstances it is not possible to ascertain whe ther ECS given after the second experience could still have had an amnesic effect on the first experience. In our procedure, we have used a single learning trial, which on the average lasts for about $20 \mathrm{sec}$, and a second experience occurring immediately after and lasting for $10 \mathrm{~min}$. Group 2 clearly shows that, after $10 \mathrm{~min}$. ECS still has an amnesic effect on the original learning. On the basis of these considerations, three hypotheses can be proposed to account for the results of Group 4: (1) ECS impairs the retention of the first experience when the effect of this experience has been already weakened by the negative interference of the second experience, this being independent of the effect of ECS upon the second experience. (2) The second experience is not affected at all by ECS and the first experience is negatively affected by both the second experience and ECS when they are given one after the other. (3) Both the first and the second experiences are affected by ECS, the impaired retention of the first experience being a combination of its weakening by ECS plus an additional weakening caused by that residue of the second experience which survived the ECS treatment. All three hypotheses imply that at the time at which the second experience would be completed, in this case $10 \mathrm{~min}$, ECS still has an amnesic effect upon the first experience (which is proved by the results of Group 2). In the first hypothesis, the second experience is seen as an event which in some way slows down or interrupts a possible consolidation process of the first experience. In the second and third hypotheses, the second experience is viewed as conflicting with the first one and the performances in the retest trials are conceived to be the result of the relative strength of the two conflicting experiences.

In any case, these results are in agreement with those obtained by Robustelli \& Jarvik (1968), using detention as an interfering experience, and, as for detention, yet another explanation can be suggested. The increased amnesic effect of ECS when given after the second experience could simply be the result of an alteration of the physiological state (for instance, an increase of level of arousal), produced by the second experience, making the animal more sensitive to ECS. Even according to this interpretation, however, the assumption underlying the stronger amnesic effect when ECS is given after the second experience is that of a direct action of ECS upon the first experience.

It can be stated in general that the validity of the assumption of a selective amnesic effect of ECS on the retention of the experience closer in time to its administration depends upon an analysis of the experimental situation. First of all, the temporal relationships of the two experiences with each other and with ECS administration have to be examined. In particular, it should be ascertained whether ECS is still effective upon the first experience at the time when the second experience is completed and, furthermore, the specific nature of each experience has to be considered independently, in respect to its sensitiveness to the amnesic effect of ECS.

\section{REFERENCES}

BARON, A. Suppression of exploratory behavior by aversive stimulation. Journal of Comparative \& Physiological Psychology, 1964,57, 299-301.

BURES, J., \& BURESOVA, O. Cortical spreading depression as a memory disturbing factor. Journal of Comparative \& Physiological Psychology, 1963, 56, 268-272.

DAVITZ, J. R., \& MASON, D. J. Socially facilitated reduction of a fear response in rats. Journal of Comparative \& Physiological Psychology, 1955, 48, 149-151.

DUNCAN, C. P. Habit reversal induced by electroshock in the rat. Journal of Comparative \& Phy siological Psychology, 1948, 41, 11-16.

GERBRANDT, L. K., \& THOMSON, C. W. Competing response and amnesic effects of electroconvulsive shock under extinction and incentive shifts. Joumal of Comparative \& Phy siological Psychology, 1964, 58, 208-211. GREENOUGH, W. T., \& SCHWITZGEBEL, R. L. Effect of a single ECS on extinction of a bar press. Psychological Reports, 1966, 19, 1227-1230.

JARVIK, M. E., \& KOPP, R. An improved one-trial passive avoidance learning situation. Psychological Reports, 1967, 21, 221-224.

MONTGOMERY, K. C. Exploratory behavior as a function of "similarity" of stimulus situation. Journal of Comparative \& Physiological Psychology, 1953,46, 129-133. 
ROBUSTELLI, F., \& JARVIK, M. E. Retrograde amnesia from detention. Physiology \& Behavior, 1968, 3, 543-547.

WILCOXON, F., \& WILCOX, R. A. Some rapid approximate statistical procedures Lederle Laboratories, Pearl River, N.Y., 1964.
NOTE

1. This research was supported by USPHS Grant MH 05319 from the National Institute of Mental Health and an Interdepartmental Institute for Training in the Neurologic and $\mathrm{Be}$ havioral Sciences Grant 5T1 MH 6418.

\section{Stimulus control of prey attack in naive rat snakes: A species duplication'}

DALE D. MORRIS and MICHAELS. LOOP, 2 Division of Biological and Medical Research, Argonne National Laboratory, Argonne, Ill. 60439

Previously unfed, newborn rat snakes (Elaphe) were found to exhibit a greater response to prey-object extracts than to a distilled-water control stimulus. Response to the different prey-object extracts was not different. The results indicate that young rat snakes accept a wide variety of prey. objects-those normally eaten by the adult and prey of a convenient size.

G. M. Burghardt (1966) has demonstrated that newborn garter snakes (Thamnophis) can be induced to attack a cotton swab containing a chemical extract from the body surface of preferred prey. These previously unfed snakes at tempt to eat a swab dipped in worm extract but refused to attack similar swabs containing horsemeat extract or distilled water. Subsequent studies (Burghardt, 1967a) revealed a high correlation between the chemical extracts most stimulating to a young snake and the food items most commonly eaten by the adult under natural conditions. Burghardt (1967b) states, "The inexperienced snake somehow can recognize, on the basis of chemical stimuli alone, what it 'should' attack as a potential prey object."

A characteristic common to all species reported on by Burghardt is that they possess no specialized food-capturing talents. No species of poisonous snakes or constrictors have been studied. Snakes investigated thus far rely solely on the "seize and swallow" technique of prey capture. Modest size and the inability to kill prey prior to ingestion dictates the selection of prey that are small and incapable of injuring the snake. The question now arises, what of the species of snakes that as adults typically feed on large, potentially dangerous animals? For example, how will a 12-g rat snake respond to the chemical stimuli of prepared extract from a 140 -g rat?

\section{METHOD}

The 11 Ss were the offspring of an inter-race mating between a male Elaphe obsoleta quadrivittata from Southern Florida and a female Elaphe obsoleta obsoleta from Eastern Tennessee. The initial clutch contained 17 eggs, of which 14 hatched. Four of the newly hatched snakes were physically deformed, and three of these died shortly after hatching. The one surviving snake had a malformed eye and tail but was used in the study: At birth, the mean weight of the Ss was $12.1 \mathrm{~g}$.
The stimulus items were distilled water. goldfish (Carassius), frog (Rana), worm (Lumbricus), cotton rat (Sigmodon), laboratory white mouse (Strain CF No. 1/Anl), adult and baby deer mice (Peromyscus), baby domestic chick (Gallus), and grasshopper (Melanoplus). Preparation involved placing the whole stimulus prey-object in 50 -deg $\mathrm{C}$ water $(10 \mathrm{ml}$ per $1.5 \mathrm{~g}$ body weight) for $1 \mathrm{~min}$. The prey-object was removed and the remaining aqueous solution was then centrifuged at $2000 \mathrm{cps}$ for $10 \mathrm{~min}$ and refrigerated at $7.2 \mathrm{deg} \mathrm{C}$ until used.

The Ss were tested after their initial molt, which occurred approximately 13 days after birth. They were moved to individual plastic containers $12 \mathrm{~h}$ prior to testing. Illumination prior to and during the experiment was provided by $60-\mathrm{W}$ red lights. The time between stimulus presentations for each $S$ was $30 \mathrm{~min}$. For each trial, a cotton swab dipped in extract was placed $2 \mathrm{~cm}$ in front of the S's snout. If no attack occurred with in $30 \mathrm{sec}$, the swab was moved slowly forward until it touched the S's snout and then removed to $2 \mathrm{~cm}$. A single trial lasted $90 \mathrm{sec}$, during which the number of tongue flicks were counted. If an attack was made, the trial was terminated and the latency was recorded to the nearest second. The entire experiment lasted $5.5 \mathrm{~h}$. Each $\mathrm{S}$ received one presentation of each stimulus item, with stimuli presented in random order.

The effectiveness of stimulation by each extract was evaluated by using Burghardt's formula. This formula is the maximum number of tongue flicks emitted by any $S$ to any stimulus, plus the length of a single trial, minus the latency of the attack in seconds. If no attack occurred, the number of tongue flicks was taken as the stimulating value of the extract. The data were analyzed by nonparametric statistical methods since the assumptions of parametric methods were not met.

\section{RESULTS}

During the 110 trials only 10 at tacks were observed. The mean latency of these attacks was $40.2 \mathrm{sec}$. For the remaining 100 trials, the number of tongue flicks for a single trial ranged from 0 ( 18 trials) to 155 (2 trials). The mean tongue flick-attack score for each stimulus item is presented in Fig. 1. The three highest mean scores were elicited by cotton rat, fish, and laboratory mouse. Only these stimuli elicited more than one attack. One attack each was elicited by frog, worm, adult deer mouse, and baby deer mouse.

Since there appeared to be a difference in the level of responding as the testing progressed, a Walsh Test (Siegel, 1956) was performed to compare the mean response of each $S$ for each stimulus item on Trials $1-5 \mathrm{vs}$ Trials 6-10. The difference was found to be 